\title{
A ESCOLA DE EDUCAÇÃO INFANTIL NO CONTEXTO DO CAMPO: PROBLEMATIZAÇÕES NECESSÁRIAS
}

EARLY CHILDHOOD SCHOOL IN THE COUNTRY SIDE CONTEXT: IMPORTANT PROBLEMATIZATION

\author{
LA ESCUELA DE EDUCACIÓN INFANTIL EN EL CONTEXTO DEL CAMPO: PROBLEMATIZACION \\ NECESARIAS
}

BOITO, Crisliane ${ }^{1}$

ALBUQUERQUE, Simone Santos de 2 (D)

\section{RESUMO}

O artigo apresenta parte dos dados gerados na pesquisa "Caracterização do atendimento de crianças de 0 a 6 anos residentes em áreas rurais do estado do Rio Grande do Sul/Brasil". As entrevistas foram realizadas com famílias e um representante do Movimento dos Trabalhadores Rurais Sem Terra, moradores do Assentamento Integração Gaúcha, onde está localizada a escola de Educação Infantil Flor da Terra. As análises revelam que naquele local a escola é um marco na qualidade de vida, fundamental para a socialização das crianças, mas que é necessária a construção de uma "Pedagogia das Raízes".

Palavras-chave: Educação Infantil. Educação no campo. Educação do campo. Prática pedagógica.

\section{ABSTRACT}

This article presentes part of the data generated in the research entitled "Caracterização do atendimento de crianças de 0 a 6 anos residentes em áreas rurais do estado do Rio Grande do Sul/Brasil". Interviews were realized with families and a representative of the Landless Rural Workers Movement (Movimento Trabalhadores Rurais Sem Terra), residents of Gaúcha Integration Settlement (Assentamento Integração Gaúcha), where Flor da Terra School of Childhood Education is located. Analyzes reveal that, this school is a milestone in the quality of life in that place, fundamental for the socialization of children, however the construction of a "Pedagogy of the Roots" is necessary.

Keywords: Child Education. Education in the countryside. Education from the countryside. Pedagogical practice.

\section{RESUMEN}

El artigo presenta parte de los datos generados en la investigación "Caracterización del atendimiento de los niños de 0 a 6 años residentes en áreas rurales del estado de Rio Grande do Sul / Brasil". Las entrevistas fueron realizadas con familias y con uno de los representante del movimiento de los Trabalhadores Rurais Sem Terra (Trabajadores rurales sin tierra) donde está localizada la Escola de Educação Infantil Flor da Terra. El análisis demuestra que en ese lugar la escuela es un marco en la cualidad de vida del contexto pesquisado, fundamental para la socialización de los niños, pero que es necesaria la construcción de una "Pedagogía de las Raíces".

Palabras clave: Educación Infantil. Educación en el campo. Practica pedagógica.

\footnotetext{
1 Universidade Federal de Campina Grande - UFCG - Campina Grande - Paraíba - Brasil

2 Universidade Federal do Rio Grande do Sul - UFRGS - Porto Alegre - Rio Grande do Sul - Brasil
} 


\section{INTRODUÇÃO}

A Educação Infantil do campo brasileira vem sendo marcada nas últimas décadas pela mobilização de mulheres, movimentos sociais, sindicatos, Ministério da Educação, e principalmente pelas ações instauradas pela Secretaria de Educação Continuada, Alfabetização, Diversidade e Inclusão - SECADI. Como resultados dessas articulações, a Educação Infantil do campo tem conquistado alguns avanços, tais como: a inserção de concepções contidas nas Diretrizes Operacionais das Escolas do Campo (Resolução CNE/CEB No 1/2002) nas Diretrizes Curriculares Nacionais para a Educação Infantil - DCNEI (Resolução CNE/CEB Nº5/2009); a elaboração de texto específico sobre as Orientações Curriculares para Educação Infantil do Campo (2010); a realização da Pesquisa Nacional sobre as condições de oferta e demanda de Educação Infantil do campo (MEC/UFRGS, 2011); a elaboração pelo Grupo de Trabalho Interinstitucional ${ }^{3}$ do documento intitulado "Educação Infantil do Campo: proposta para a expansão da política" (2014), entre outros.

No entanto, embora reconheçamos a importância dessas conquistas, consideramos que o impacto destes documentos norteadores, bem como, da pesquisa desenvolvida a nível nacional, ainda aparecem de maneira bastante tímida na concretude da vida das crianças do campo brasileiras. Em estudos realizados por diferentes pesquisadoras, tais como, Rosemberg e Artes (2011), Evans e Kosec (2011), Kappel, Carvalho e Kramer (2001) são apresentados dados que nos levam a considerar que são as crianças pequenas, negras e que vivem no campo o segmento da população que mais sofre com as desigualdades econômicas em nosso país.

A Pesquisa Nacional por Amostra de Domicílios - PNAD (2009) e a Pesquisa Nacional Caracterização das práticas educativas com crianças de 0 a 6 anos residentes em área rural (2011) revelam que é também esse o segmento da população brasileira que em todas as regiões do país apresenta o menor índice de matrículas na Educação Infantil. Para o Fundo das Nações Unidas para a Infância - UNICEF, está desigualdade em termos de oferta educacional pode ser também a responsável pela desigualdade social das crianças pequenas que vivem em áreas rurais (UNICEF, 2014).

Reconhecemos, diante dos dados, que discutir a oferta do acesso a Educação Infantil do campo é extremamente importante. No entanto, em nossas imersões em campo durante a realização da pesquisa "Caracterização do atendimento de crianças de 0 a 6 anos residentes em áreas rurais do estado do Rio Grande do Sul/Brasil", identificamos o quanto também é urgente fomentar a reflexão sobre a valorização dos modos de vida e das especificidades culturais das crianças do campo nas escolas no campo para que não haja uma "[...] transposição de modelos instituídos a partir da dinâmica social e espacial urbana" (SECADI, 2012, p.4).

\footnotetext{
${ }^{3}$ Este documento foi produzido- GTI- instituído pela Portaria № 6/2013 e foi assinado pelos Ministros de Estado da Educação, do Desenvolvimento Agrário e do Desenvolvimento Social e Combate à fome.
} 
Nos alinhamos ao entendimento de Silva e Pasuch (2010) apresentado no documento “Orientações Curriculares para a Educação Infantil do Campo" à respeito do quanto é

\begin{abstract}
[...] importante considerar que as crianças do campo possuem seus próprios encantos, modos de ser, de brincar e de se relacionar. As crianças do campo têm rotinas, experiências estéticas e éticas, ambientais, políticas, sensoriais, afetivas e sociais próprias. Os tempos de plantar e de colher, os ciclos de produção, de vida e de morte, o tempo das águas e estiagem, as aves e bichos do mato, dos mangues, dos pantanais, a época de reprodução dos peixes, aves, pássaros e outros animais, o amanhecer e o entardecer, o tempo de se relacionar com os adultos e crianças, tudo isso marca possibilidades diferenciadas de viver a infância, na multiplicidade que o campo brasileiro se configura, numa relação orgânica com a terra que pinta os pés com força e marca a pele, os dedos e as unhas e delineia sorrisos. (2010, p.1).
\end{abstract}

Kolling, Cerioli e Caldart nos apresentam, nesta perspectiva, que precisamos de uma educação no/do campo, em que [...] No: o povo tem direito a ser educado no lugar onde vive; Do: o povo tem direito a uma educação pensada desde o seu lugar e com a sua participação, vinculada à sua cultura e às suas necessidades humanas e sociais. (2002, p. 18, grifos nossos).

Neste contexto, enfatizando a perspectiva histórica que "[...] as crianças de 0 a 5 anos e onze meses residentes em áreas rurais vivem um processo de ocultamento, omissão e acesso desigual às políticas públicas" (GTI, 2014, p.6), e de que a oferta educacional aos bebês e crianças pequenas em escolas de Educação Infantil no campo, quando acontece, não dialoga com os documentos e referenciais norteadores da Educação Infantil e da Educação do Campo (SILVA; LUZ, 2011), é que justificamos a relevância deste artigo. Nesta escrita, buscaremos visibilizar o entendimento de seis famílias e de um representante do Movimento dos Trabalhadores Rurais Sem Terra - MST no que versa sobre a escola de Educação Infantil localizada dentro do assentamento Integração Gaúcha, na cidade de Eldorado do Sul/RS.

\section{O CONTEXTO DA PESQUISA}

O trabalho de campo que resulta as discussões que apresentaremos nesta escrita foi realizado no município de Eldorado do Sul, que no ano de 2015, segundo a Radiografia de Educação Infantil elaborada pelo Tribunal de Contas do Estado do Rio Grande do Sul - TCE/RS, possuía uma população total 2.026 crianças de 0 a 3 anos e de 1.092 crianças de 4 a 5 anos, sendo que desse total o percentual de $10 \%$ era de crianças que residentes em área rural.

A seleção do município para a realização deste estudo ocorreu por três razões principais, a saber: (1) possuir uma Escola Municipal de Educação Infantil que atende crianças de 0 a 6 anos localizada em área rural; (2) ter acesso facilitado para as pesquisadoras (distante $15 \mathrm{~km}$ de Porto Alegre); (3) ter apresentado receptividade da Secretaria da Educação para o desenvolvimento do estudo. 
A comunidade pesquisada integra o Assentamento Integração Gaúcha, popularmente conhecido como assentamento IRGA4, que se constituiu em 1991 quando um grupo de pessoas integrantes do MST tomaram posse da terra cedida pelo Governo do Estado do Rio Grande do Sul na cidade de Eldorado do Sul, através do Instituto Nacional de Colonização e Reforma Agrária - INCRA. A posse de terra, da forma como ocorreu, implicou aos assentados a não obtenção de recursos destinados à moradia, e ainda, a condição imposta pelo governo de que deveriam trabalhar por um período em cooperativas.

No início do assentamento, as famílias enfrentavam condições precárias e muitas dificuldades. Em entrevistas, as famílias relataram que mesmo após terem conquistado o direito a terra ainda moraram por um longo período em barracos de lona, sem água, luz e sem estrada. Outra característica do assentamento Integração Gaúcha foi de que seus integrantes, inicialmente, eram em sua maioria homens solteiros, fazendo assim com que muitas famílias fossem se constituindo com o passar dos anos, e consequentemente, a partir disso, aumentando o número de crianças no local. Dessa forma, com o passar dos anos no assentamento foi se fazendo cada vez mais necessário um espaço onde as crianças pudessem ficar para que as mulheres-mães pudessem "ajudar" 5 seus companheiros no cultivo da terra e na cooperativa.

Num primeiro momento, quando o trabalho de todos os assentados estava vinculado à cooperativa, a solução encontrada pelo coletivo das mulheres-mães para poderem ajudar na horta ${ }^{6}$ foi de que seus filhos ficassem aos cuidados de algumas delas, enquanto as outras realizavam o trabalho junto aos homens. Durante o período de pesquisa os relatos evidenciaram que foram diversos os locais que as crianças ficaram aos cuidados de mulheres do movimento, tais como, debaixo de uma árvore, depois de uma varanda e ainda, em um pequeno galpão do movimento, que consistia em uma sala pequena, um banheiro e uma cozinha que atendia até 13 crianças, que sua por vez, não podiam estar usando fraldas, pois não havia trocador.

No ano de 2003, com o fim da exigência do governo para o trabalho em cooperativa, muitas famílias decidiram não mais participar dessa organização e, deste modo, passaram a não ter mais um lugar específico para deixarem seus filhos enquanto trabalhavam na terra. Neste período, com um número de 32 crianças entre zero e seis anos de idade no assentamento, as famílias iniciaram uma busca por creches e pré-escolas na cidade para poderem trabalhar com mais tranquilidade. No entanto, tal solução era insatisfatória devido à distância do assentamento até as instituições que atendiam as crianças pequenas em área urbana.

Diante de todos esses aspectos, o desejo de conquistar um lugar adequado onde as crianças pudessem ser atendidas no próprio assentamento passou a ser reivindicado, especialmente pelas

\footnotetext{
${ }^{4}$ Segundo Campos (2006), o nome dado ao assentamento deve-se ao fato ter se constituído em uma propriedade de autarquia do governo Estadual - IRGA /Instituto Rio Grandense do Arroz. Como as famílias que constituem o assentamento eram oriundas de diversas regiões do Estado, as pessoas que moravam na cidade passaram a nominar os assentados como "os colonos do IRGA".

${ }^{5}$ Durante a pesquisa foi possível compreender o sentido da expressão das mulheres assentadas de "ajudar seus companheiros", pois não possuíam condição de autonomia e de trabalho, já que não tinham com quem deixar os filhos.

${ }^{6}$ Horta foi o nome dado pelas famílias ao espaço de trabalho na terra.
} 
mulheres que viam nesta conquista a possibilidade de sua emancipação. Em entrevista, um dos representantes do movimento social explicou que a opção por buscarem naquele contexto o atendimento em uma escola de Educação Infantil e não a experiência de cirandas, que é característica prioritária dos assentamentos do movimento, deu-se pelo desejo de que tivessem um espaço de educação formal dentro do assentamento onde as crianças pudessem ficar próximas de suas famílias, bem como, pela intenção de ter a participação do poder público, uma vez que não tinham conseguido nenhum auxílio governamental quando chegaram ao assentamento Integração Gaúcha.

Neste sentido, o ano de 2003 foi marcado por manifestações, tendo as mulheres como principais articuladoras, visando a construção de uma escola de Educação Infantil dentro do assentamento. Em entrevistas com famílias foram lembradas as marchas até a cidade, as audiências na prefeitura e na Secretaria de Educação e também a ocupação das mulheres/mães do gabinete do prefeito.

Em setembro de 2006, após muita mobilização foi inaugurada no assentamento a Escola Municipal de Educação Infantil Arco-Íris, que mais tarde, a partir de reuniões com a comunidade escolar, foi renomeada Escola Municipal de Educação Infantil (EMEI) Flor da Terra. No ano de 2016, a escola atendia crianças de 0 a 4 anos em turno integral, sendo a grande maioria oriundas do próprio assentamento. Também crianças que residem na cidade de Eldorado do Sul frequentam a escola, realizando desse modo um processo inverso ao que tradicionalmente conhecemos, onde as crianças do campo são remanejadas ${ }^{7}$ para a cidade.

Salientamos que desde o ano de 2013, em virtude da Emenda Constitucional 59/2009, que determina a obrigatoriedade de matrícula para crianças de 4 e 5 anos, as crianças de 4 anos passaram a ser matriculadas em turno parcial em turma de pré-escola, na escola de Ensino Fundamental Almirante Tamandaré, localizada ao lado da escola de Educação Infantil. A necessidade de criar turmas de Educação Infantil na Escola de Ensino Fundamental deu-se em razão das limitações de espaço para atender a demanda das famílias assentadas sem, desse modo, precisar limitar a oferta de vagas para as crianças de 0 a 3 anos.

Consideramos que o processo de conquista da EMEI Flor da Terra é semelhante ao modo como ocorreu em creches e pré-escolas nos centros urbanos, onde os movimentos sociais liderados por mulheres tiveram um papel fundamental. No contexto do assentamento Integração Gaúcha, a implementação da escola de Educação Infantil está fortemente relacionada à busca, pelo coletivo de mulheres, a igualdade de gênero em relação e reconhecimento do trabalho feminino no campo. Nesse sentido, nosso desejo de investigar este contexto deu-se por reconhecer as especificidades da demanda e oferta de Educação Infantil para as crianças do campo.

\footnotetext{
${ }^{7}$ As crianças que vêm da cidade são trazidas pelos pais ou por transporte privado, (vans escolares pagas pelos pais), não sendo atendidas, portanto, por transporte público.
} 


\section{CONSTRUÇÃO METODOLÓGICA DA PESQUISA}

Nossa opção metodológica pela pesquisa qualitativa de abordagem etnográfica se deu, principalmente, pela relação que se estabelece entre pesquisador, pesquisado e o contexto da pesquisa. Para Victoria, Knauth e Hassen (2000):

[...] o método que contempla esta abordagem procura fazer com que os investigadores trabalhem e treinem o seu olhar com profundidade sobre seus sujeitos de pesquisa, possibilitando ao pesquisador compreender a forma da vida das pessoas do qual pretende investigar. (p.37)

A esse respeito, nos inspiramos também em Stake quando reconhece que o método qualitativo é "[...] excelente para analisar as formas reais e existentes que as pessoas ou as organizações estão usando para funcionar" (2011, p.12).

Desse modo, inicialmente, procuramos manter um contato mais próximo com lideranças do assentamento, que além de se tornarem nosso "cartão de visitas" na escola e nas famílias pesquisadas, foram fundamentais para nos apresentar dados da história da comunidade e pessoas de referência deste processo histórico. Consideramos que esse método se aproxima do que revelou Víctoria, Knauth e Hassen (2000) sobre o quanto a relação de proximidade e confiança entre pesquisador e pesquisado implica na qualidade dos dados gerados.

Em nossas imersões de campo estivemos apoiadas nos cinco desdobramentos da etnografia considerados por Fonseca (1998) como importantes "pistas" na função como pesquisadoras: estranhamento, esquematização, desconstrução, comparação e a sistematização do material em modelos alternativos. Para a realização da investigação foi necessário um cuidado minucioso nas escolhas das técnicas investigativas e dos sujeitos pesquisados, sendo importante desenvolver aptidão para observar, obter dados e informações, destacando a imparcialidade necessária para adquiri-los e processá-los.

Nossa inserção no contexto pesquisado iniciou no mês de janeiro de 2013, contemplando visitas ao assentamento Integração Gaúcha onde permanecemos produzindo dados até o final do mês de junho de 2015. Foram realizadas trinta idas até o assentamento para o desenvolvimento da pesquisa, com observações ${ }^{8}$ na escola e entrevistas com famílias, representantes do movimento social e representante da escola. Ainda, realizamos a análise do Projeto Político Pedagógico e conversas com crianças, com idades entre 2 e 4 anos. $O$ intuito de realizar uma aproximação em diferentes níveis deu-se no sentido de obter uma apreensão mais ampla da realidade conforme propõe Victoria, Knauth e Hassen (2000).

Os dados que serão explorados neste artigo são originados de entrevistas com seis famílias que possuem ou já possuíram seus filhos matriculados na escola de Educação Infantil e, também, de

\footnotetext{
${ }^{8}$ Tanto na abordagem da observação quanto das entrevistas foram utilizados roteiros semiestruturados previamente elaborados no grupo de pesquisa.
} 
entrevista com um dos representantes do movimento social. Tais entrevistas foram gravadas e transcritas de modo fidedigno visando visibilizar as narrativas dos sujeitos entrevistados, através de seus modos de contar, analisar e explicar o contexto em que vivem.

\section{ESCOLA MUNICIPAL DE EDUCAÇÃO INFANTIL FLOR DA TERRA: A CONQUISTA PELO DIREITO À EDUCAÇÃO}

A conquista da EMEI Flor da Terra no contexto do Assentamento Integração Gaúcha ocorreu a partir do movimento de luta iniciado pelas mulheres, mas integrada pelo coletivo da comunidade no decorrer do processo. Essa articulação contribuiu com a organização das famílias, principalmente ao consolidar a garantia o direito das crianças pequenas de frequentarem uma instituição de educação próxima de suas residências.

Nesta direção, podemos destacar que o direito das crianças pequenas do campo ultrapassa a questão de oferta de vagas, mas vislumbra principalmente a qualidade desta oferta nas instituições que atendem as crianças moradoras das áreas rurais. $O$ fato de a oferta ser próxima das residências das crianças é um direito, que aliado a realização de propostas pedagógicas articuladas aos modos de ser e viver do campo, significam a real garantia do que está apresentado nos documentos legais. As Diretrizes Curriculares Nacionais para a Educação Infantil apresentam, por exemplo, que:

\footnotetext{
$\S 3^{\circ}$ As propostas pedagógicas da Educação Infantil das crianças filhas de agricultores familiares, extrativistas, pescadores artesanais, ribeirinhos, assentados e acampados da reforma agrária, quilombolas, caiçaras, povos da floresta, devem:

I - reconhecer os modos próprios de vida no campo como fundamentais para a constituição da identidade das crianças moradoras em territórios rurais;

II - ter vinculação inerente à realidade dessas populações, suas culturas, tradições e identidades, assim como as práticas ambientalmente sustentáveis;

III - flexibilizar, se necessário, calendário, rotinas e atividades respeitando as diferenças quanto à atividade econômica dessas populações;

IV - valorizar e evidenciar os saberes e o papel dessas populações na produção de conhecimentos sobre o mundo e sobre o ambiente natural;

$\mathrm{V}$ - prever a oferta de brinquedos e equipamentos que respeitem as características ambientais $\mathrm{e}$ socio-culturais da comunidade. (BRASIL, 2009, Art. $8^{\circ}$, p.21).
}

Desse modo, a partir das entrevistas com as famílias que residem no assentamento, evidenciamos a trajetória de luta pelo direto à educação das crianças pequenas articulada aos seus entendimentos sobre as condições de oferta e das propostas pedagógicas, no que se refere à Educação Infantil no/do campo. O orgulho da vida no campo e a importância dada à escola de Educação Infantil considerando-a inclusive como "uma benção", uma vez que, segundo as famílias entrevistadas, possibilita a autonomia das famílias, especialmente das mulheres, merece destaque. Concomitante a isso, as famílias compreendem que é preciso que esteja presente "a cultura de viver no campo" nas práticas pedagógicas vividas por seus filhos. 
Neste âmbito, o representante do Movimento dos Trabalhadores Rurais Sem Terra entrevistado considera que o trabalho pedagógico da escola deveria estar voltado para as raízes do campo, sendo fundamentado assim em uma Pedagogia das Raízes. A partir de uma entrevista bastante minuciosa compreendemos que o conceito "Pedagogia das Raízes" é problematizado pelo movimento a partir de quatro ações principais:

- O reconhecimento de uma alimentação mais qualificada dentro da própria instituição, do que sai da terra, ou seja, como e o que se produz;

- O reconhecimento da história e da origem daquela comunidade;

- A integração dos professores naquele contexto, ou seja, que os docentes busquem uma permanente formação, tendo em vista um constante remanejo e olhar para aquela especificidade, destacando como base pedagógica a valorização da cultura e da realidade da comunidade;

- A interação do movimento social como a comunidade escolar.

Complementando a explicação, o entrevistado considerou que a efetividade das ações acima citadas possibilitaria vivências contextualizadas às crianças do assentamento que frequentam a escola de Educação Infantil. Extrapolando esse fato, legitimaria também para as crianças que vem da cidade o entendimento sobre a importância dos trabalhadores do campo, tendo assim, importantes articulações na relação campo/cidade- rural/urbano.

Neste mesmo sentido, a mãe de uma das famílias entrevistadas reflete o quanto ações que desmitificam a ideia de área rural como lugar atrasado, passando a valorizar a cultura e a realidade local podem possibilitar a diminuição do preconceito em relação ao campo como relata abaixo:

[...] porque chega lá na cidade vem o preconceito. Ah, porque tu é colono né! Então queira ou não, sempre tem aquela gurizada. Ah, porque tu é colono, porque não sei o que... mas, só que eles também são inocentes, não conhecem a realidade do que é um assentamento né? Pra eles, acham que sendo colono tem que ser feio, sujo, sei lá. É uma realidade diferente (mãe de família entrevistada em 14/02/2014).

No entanto, segundo o representante do movimento, um fator que tem dificultado que vivências mais ligadas a uma "Pedagogia das Raízes" se efetivem, envolve os professores que trabalham na escola:

É rica a ideia de eles terem uma horta mais educativa e tentar resgatar as nossas raízes né. [...] A ideia é que se tenha bastante serviço voltado a raízes nossa. [...] aí a dificuldade também é o profissional, o professor é coisa que vem do meio urbano então fica difícil trabalha essas questões né. Os professores não são daqui. [...] E é isso, mostrar toda a história para passar o significado que tem. Olha isso aqui foi teu pai quem plantou e tal. [...] Tem umas pessoas já que acham "não, mas isso já é passado", mas temos que entender que é construir o passado para valorizar o futuro. Por isso, mostrar para as crianças que gente não chegou aqui e tava tudo 
Para o representante do movimento social, a alternativa para se concretizar a "Pedagogia das Raízes" seria de que fosse feito de modo permanente uma parceria entre escola, representantes do movimento e famílias assentadas:

[...] uma espécie de assessoria técnica na escola e voltar a questão para nossas raízes, mostrar de onde vem o alimento, reciclar, plantar. Esse é o nosso ambiente, daqui que a gente tira 0 nosso sustento, valorizar essa terra que a gente conquistou. Isso precisa aprofundar, esse trabalho é sempre isolado. Tinha que ser permanente [...] (Entrevista realizada em 12/05/2014).

Diante do exposto, é possível considerar a partir das entrevistas, tanto com as famílias quanto com o representante do movimento social, que existe a compreensão de que a luta pela Educação Infantil no Campo vai além da infraestrutura e oferta de vagas. O trabalho pedagógico articulado com as especificidades da vida e a cultura dos povos do campo foram apontados e evocados como importante articulador para de fato legitimar o direito das crianças de modo coerente.

Ainda, a partir do contexto pesquisado, outra observação é pertinente de ser refletida neste artigo sobre a Educação Infantil no/do campo. Trata-se do fato de a Escola de Educação Infantil Flor da Terra ser considerada pelos entrevistados como o único local de encontro e de convívio das crianças e de experiências de socialização com seus pares de diferentes faixas etárias. Não havia no contexto pesquisado, no período que realizamos a pesquisa, outro local de encontro das crianças como, por exemplo, praças, igrejas, quadras de esportes comunitárias. Tivemos conhecimento apenas da Cooperativa dos Trabalhadores Rurais Sem Terra, que possui um salão e um local aberto para realização de algumas atividades dos cooperativados, mas estas ações são eventuais.

As famílias entrevistadas relataram que as crianças apenas convivem com "os de casa", raramente encontram os vizinhos, mesmo que as casas sejam próximas umas das outras, não possuem o costume de oportunizar socialização entre as crianças. Nesse viés, outro aspecto que nos chamou atenção foi de que quase todas as residências eram cercadas por grades e/ou outros tipos de limitadores entre o espaço de cada família, característica comumente observada em espaços urbanos e ainda pouco vista, em nossas experiências, em contextos de campo.

As observações realizadas na EMEI Flor da Terra apontam uma dimensão fundamental para reflexão e para pensar em princípios importantes que, a nosso ver, precisam nortear as práticas pedagógicas nas escolas de Educação Infantil do campo: a promoção de encontros entre as crianças de diferentes faixas-etárias. Sublinhamos a importância dessas vivências de integração das faixas etárias uma vez que, como apresentamos acima, são limitadas.

Este debate é apresentado no documento "Práticas cotidianas na Educação Infantil- Bases para a reflexão sobre as orientações curriculares" (BRASIL, 2009) que aborda uma discussão importante sobre o conceito de "culturas infantis" e de "socialização", destacando a importância da 
escola como um espaço de troca e produção de culturas entre as crianças de diferentes faixas etárias. Neste sentido, é afirmado que:

\begin{abstract}
A expressão "culturas infantis". de uso mais recente. se refere às confiauracões esnaciais e temnorais do contexto em aue as criancas vivem com outras criancas. mediadas bela cultura. Para as criancas. essas producões lhes possibilitam dar sentido ao mundo. As criancas. em suas culturas infantis recomnõem a cultura material e simbólica de uma sociedade. Flas fazem sua releitura do mundo. isso é. leem o mundo adicionando novos elementos deracionais. recriando-o e reinventando-o. Na educacão infantil. a oraanizacão do temno e do esnaco precisa oferecer a onortunidade de momentos de troca com outras criancas e de brincadeiras due efetivamente promovam aprendizagens, garantindo o desenvolvimento. (BRASIL, 2009, p.31 - 32).
\end{abstract}

A partir deste conceito, o documento destaca que a escola como um contexto social precisa envolver espaços e tempos de brincadeiras com crianças pequenas, bebês e crianças maiores, destacando que:

\begin{abstract}
「...1 os estabelecimentos educacionais nara criancas pequenas precisam revisar a oraanizacão das turmas anenas por faixa etária similar e probiciar obortunidades de interacões tanto de criancas da mesma idade duanto de criancas de idades diferentes. na nersnectiva de favorecer a transmissão e a reelahoracão das culturas de infância. Alđumas nersnectivas de comnreensão da infância mostram que ela não é abenas um momento no desenvolvimento das pessoas ou de uma faixa etária esnecífica. A infância não node ser vista como uma etana estanđı da vida. alon a ser sunerado ou. ainda. aue termina com a iuventude. A infância deixa marcas. permanece e habita os seres humanos ao lonao de toda a vida. como uma intensidade. uma presenca. um ieito de ser e estar no mundo. Como uma reserva de sonhos, de descobertas, de tristezas, de encanto e entusiasmos. (2009, p. 32)
\end{abstract}

Outro documento que destaca as interações entre as crianças no contexto da escola para crianças pequenas e bem pequenas são os "Indicadores de Qualidade na Educação Infantil” (2009). Nesta publicação de auto-avaliação da qualidade das instituições de Educação Infantil (MEC, 2009), a terceira dimensão é denominada Interações e questiona se "As professoras organizam periodicamente espaços, brincadeiras e materiais que promovem oportunidades de interação entre crianças de diferentes faixas etárias?" (p.47).

Estes dois documentos indutores de políticas e práticas na Educação Infantil, consolidam nosso argumento sobre a importância de vivências e integração das faixas etárias uma vez que, como apresentamos acima, são limitadas no contexto pesquisado. Portanto, a escola como lugar de encontro entre as crianças e de produção de cultura entre os pares, nos leva a pensar que a organização dos tempos e espaços das instituições no campo, precisam necessariamente privilegiar as relações entre grupos de diferentes faixas-etárias.

O espaço necessita evidenciar que é possível construir relações, sendo assim, experiências coletivas devem ser planejadas. Em nossa análise, estas relações podem ser ampliadas entre os sujeitos da comunidade, famílias, profissionais da escola, enfim, consolidar a escola como um espaço de troca e interação.

A partir dos períodos de observação, foi possível também considerar que embora as crianças 
vivam em meio à natureza, o tempo vivenciado na instituição em sua maior parte foi nos espaços internos, predominando as salas de referência. Dos onze turnos alternados que realizamos observações na escola de Educação Infantil Flor da Terra, em apenas um turno, as crianças tiveram possiblidade de uma breve exploração do pátio externo.

A justificativa das docentes para a não utilização do espaço do pátio está implicada no reduzido número de materiais disponíveis para exploração das crianças como balanços, gangorras e brinquedos comuns a esses espaços. Entendemos, no entanto, que a riqueza de materiais que a natureza oferece encontrados nos arredores da escola poderia ser utilizada para redimensionar possibilidades de construção de experiências e aprendizagens no dia a dia da escola.

Gandhy Piorski em sua obra intitulada "Brinquedos do chão; a natureza, o imaginário e o brincar" (2016), considera que é através do brincar com os elementos da fauna e da flora que ocorrem importantes percursos da imaginação. Neste sentido, os elementos que fazem parte do cotidiano das crianças e de suas famílias como folhas, madeiras, árvores, sementes, cascas, pedras, troncos, chás, plantas e ervas poderiam ser utilizados também no espaço da escola, considerando um material de pesquisa e construção a partir das múltiplas aprendizagens e descobertas das crianças.

\section{CONSIDERAÇÕES FINAIS}

No contexto pesquisado ficou ressaltado o (re) conhecimento das famílias em relação a importância da oferta de Educação Infantil no assentamento, considerando a "creche uma benção para as famílias e para as crianças", já que a instituição é considerada como um local de encontro entre os pares e possibilidade de interações, brincadeiras e aprendizagens.

Consideramos que para os sujeitos pesquisados, o direito a Educação Infantil foi um marco na qualidade de vida no campo no âmbito de reforma agrária, mas apontam que é necessário um trabalho pedagógico que articule as especificidades da vida e dos povos do campo, indicando a construção de uma "Pedagogia das Raízes".

Sendo assim, a experiência de Educação Infantil destas famílias assentadas que já possuem seus filhos na escola remonta um cenário, levando, por um lado, a reconhecerem e buscarem cada vez mais esse direito, e por outro a exigência de se ter essa oferta aliada a uma proposta adequada e qualificada.

Destacamos que a concepção "Pedagogia das Raízes" enunciada pelo representante do movimento social, que já teve suas três filhas matriculadas na EMEI Flor da Terra, evidencia um conceito importante que pode perseguir a construção da proposta pedagógica e as práticas cotidianas vivenciadas por crianças e adultos na Educação Infantil no/do campo.

Acreditamos que o reconhecimento da importância da Educação Infantil para as crianças e famílias do campo faz parte de um projeto social, econômico e político do país, e para isso a força mobilizadora dos movimentos sociais continua fundamental para que todas as conquistas no plano 
legal se efetivem no plano real para os povos do campo.

\section{REFERÊNCIAS}

1. BARBOSA, Maria Carmen Silveira et. al. Oferta e demanda de educação infantil do campo. Porto Alegre, RS: Evangraf, 2012.

2. BODGAN,C. Robert; BIKLEN, Sari. Investigação Qualitativa em Educação. Portugal: Porto LDTA, 1994.

3. BRASIL. Ministério da Educação. Secretaria da Educação Básica. Indicadores da Qualidade na Educação Infantil. Brasília: MEC/SEB, 2009.

4. BRASIL. Ministério da Educação. Secretaria da Educação Básica. Práticas cotidianas na Educação Infantil- Bases para a reflexão sobre as orientações curriculares Brasília: MEC/SEB/COEDI, 2009.

5. BRASIL. Conselho Nacional de Educação (CNE). Câmara de Educação Básica. Resolução n.1, de 3 de abril de 2002. Institui diretrizes operacionais para a educação básica nas escolas do campo. Brasília, DF, 2002.

6. BRASIL. Instituto Brasileiro de Geografia e Estatística (IBGE). Pesquisa Nacional por Amostra de Domicílios - PNAD. 2009.

7. BRASIL. Ministério da Educação (MEC). Conselho Nacional de Educação. Resolução n.2, de 28 de abril de 2008. Estabelece diretrizes complementares, normas e princípios para o desenvolvimento de políticas públicas de atendimento da Educação Básica do Campo. Brasília, DF, 2008.

8. BRASIL. Ministério da Educação (MEC). Conselho Nacional de Educação. Resolução n.5, de 17 de dezembro de 2009. Diretrizes Curriculares Nacionais para a Educação Infantil. Brasília, DF, 2009.

9. BRASIL. Ministério da Educação (MEC). Relatório Síntese da Pesquisa Nacional Caracterização das práticas educativas com crianças de 0 a 6 anos de idade residentes em área rural. Brasília, DF, 2012.

10. BRASIL. Ministério da Educação (MEC). Secretaria de Educação Continuada, Alfabetização, Diversidade e Inclusão - Secadi. Educação do Campo: marcos normativos. Brasília, DF, 2012.

11. CAMPOS, Cristhiane Senhorita Soares. Educação infantil pública: uma ferramenta para ampliar a autonomia de mulheres-mães em áreas de reforma agrária. Eldorado do Sul. 2006. (não publicado). 
12. EVANS, David; KOSEC, Katrina. Educação Infantil: Programas para a geração mais importante do Brasil. São Paulo: Documento do Banco Mundial, 2011.

13. FELIPE, Eliana da Silva. Infância de assentamento e suas temporalidades históricas. In: SILVA, Isabel de Oliveira; SILVA, Ana Paula Soares; MARTINS, Aracy Alves (Orgs.). Infâncias do campo. Belo Horizonte: Autêntica, 2013. p. 25- 40.

14. FONSECA, Claúdia. Pesquisa etnográfica e educação: quando cada caso não é um caso. IN: XXI Reunião Anual da ANPED, 1998, Caxambu. ANAIS DAXXI REUNIÃO ANUAL DA ANPED. Contagem, MG. 1998, p 58- 77.

15. KAPPEL, Maria Dollores Bombardelii, Carvalho, Maria Cristina; Kramer, Sônia. (2001). Perfil das crianças de 0 a 6 anos que frequentam creches e pré-escolas: uma análise dos resultados da pesquisa sobre padrões de vida/IBGE. Revista brasileira de educação, Rio de Janeiro, n¹6, abr. 2001.

16. KOLLING, Edgar Jorge; CERIOLI, Paulo Ricardo; CALDART, Roseli Salete. Educação do campo: Identidade e Políticas Públicas. Brasília: Coleção Por Uma Educação do Campo, V.4, 2002.

17. PIORKI, Gandhy. Brinquedos de chão: a natureza, o imaginário e o brincar. Petropólis: 2016, 152 p.

18. RIO GRANDE DO SUL (Estado). Tribunal de Contas do Estado do Rio Grande do Sul Radiografia de Educação Infantil, 2015.

19. ROSEMBERG, Fúlvia. Narrativas adultas sobre lugares de vida de crianças brasileiras: infâncias do campo. SILVA, Isabel de Oliveira; SILVA, Ana Paula Soares; MARTINS, Aracy Alves (Orgs.) Infâncias do campo. Belo Horizonte: Autêntica,2013. p. 249-278.

20. ROSEMBER, Fúlvia; ARTES, Amélia. O rural e o urbano na oferta de educação para crianças de até 6 anos. In: BARBOSA, Maria Carmen Silveira Barbosa et al (Org.). Oferta e demanda da educação infantil no campo. Porto Alegre: Evangraf, 2012, p.13 - 69.

21. SILVA, Ana Paula Soares; PASUCH, Jaqueline; SILVA, Juliana Bezzon. Educação Infantil do campo. São Paulo: Cortez, 2012.

22. SILVA, Ana Paula Soares; PASUCH, Jaqueline. Orientações curriculares para a Educação Infantil do Campo. Seminário Nacional Currículo em Movimento: perspectivas atuais, Belo Horiozonte. Anais, Belo Horizonte: 2010. 
23. SILVA, Isabel de Oliveira; RODRIGUES, Iza Rodrigues da Luz. Espaços, ambientes e contextos: reflexões sobre a Educação Infantil para crianças de 0 a 6 anos residentes em área rural em dois municípios da região sudeste do Brasil. In: BARBOSA, Maria Carmen Silveira et al (Org.). Oferta e demanda da educação infantil no campo. Porto Alegre: Evangraf, 2012, p. 181-218.

24. STAKE, Robert E. Pesquisa qualitativa: estudando como as coisas funcionam. Porto Alegre: Penso, 2011.

25. UNICEF. Campanha Nacional pelo Direito à Educação. O enfrentamento da exclusão escolar no Brasil. Brasília, DF, 2014.

VICTORIA, Ceres Gomes; KNAUTH, Daniela Rova; HASSEN, Maria de Nazareth Agra. Pesquisa Qualitativa em Saúde. Porto Alegre: Tomo Editorial, 2000.

\section{Crisliane Boito}

Professora na Unidade Acadêmica de Educação Infantil da Universidade Federal de Campina Grande (UAEI/UFCG). Pedagoga e Mestra em Educação pela Universidade Federal do Rio Grande do Sul (UFRGS). Pesquisadora colaboradora do CLIQUE - Grupo de Pesquisa em Linguagens, Currículo e Cotidiano de bebês e crianças pequenas/UFRGS, do GEIN - Grupo de Estudos de Educação Infantil/UFRGS, e do GRÃO - Grupo de Estudos e Pesquisas Infâncias, Educação Infantil e Contextos Plurais.

\section{Simone Santos de Albuquerque}

Professora Associada da Faculdade de Educação da Universidade Federal do Rio Grande do Sul (UFRGS), atuando no Departamento de Estudos Especializados (DEE) na área de Educação Infantil. Pesquisadora e vice-líder do Grupo de estudos em Educação Infantil e Infâncias(GEIN/UFRGS) na linha de pesquisa Políticas e Pedagogias da Educação Infantil. Pesquisadora do Núcleo de Estudo em Educação das Infâncias (NEPE/FURG). Militante do Movimento Interfóruns de Educação Infantil do Brasil- MIEIB e Membro da Coordenação do Colegiado do Fórum Gaúcho de Educação Infantil- FGEI.

\section{Como citar este documento:}

BOITO, Crisliane; SANTOS DE ALBUQUERQUE, Simone. A escola de educação infantil no contexto do campo: problematizações necessárias. Reflexão e Ação, Santa Cruz do Sul, v. 27, n. 1, dez. 2018. ISSN 1982-9949. Disponível em: <https://online.unisc.br/seer/index.php/reflex/article/view/10749>. Acesso em: doi:https://doi.org/10.17058/rea.v27i1.10749. 